\title{
The Design of Switching Mode Power Supply Charger Based on PFC
}

\author{
Ya-long LIU ${ }^{1, a}$, Guan-yue ZHANG, Kuang-cheng LI \\ ${ }^{1}$ Academy of armored force Beijing 100072, China \\ aarthlonliu@189.cn
}

Keywords: Switching Mode Power Supply, PFC, Double forward converter.

Abstract. design a Switching Mode Power Supply Charger with a power factor correction. Discuss the design scheme of main circuit and control circuit. Expound the calculation method of the key element parameters. The experiments indicate that the device get a good performance on output and reliability. The charger is appropriate for all types of battery.

\section{Introduction}

This paper discusses the development of the storage battery charger with a power factor correction. The first stage uses continuous conduction mode(CCM) of the average current mode PFC circuits. The advantage is that it can operate over a wide input voltage range(usually 90-270v AC)[1], by this way it can overcome the conventional Switching Mode Power Supply input voltage range narrower problems, and obtain high power factor. The second stage uses interleaved two-transistor forward circuit. The advantage is a smaller transformer can be used to obtain higher output power. Parallel mode makes the conduction ratio is 2 times of the original ratio to reduce the maximum peak of output voltage, we can use small withstand voltage of power devices. Input voltage and current ripple is reduced to the half, frequency is doubled, and the volume of the input filter is reduced accordingly. The system principle block diagram as follows:

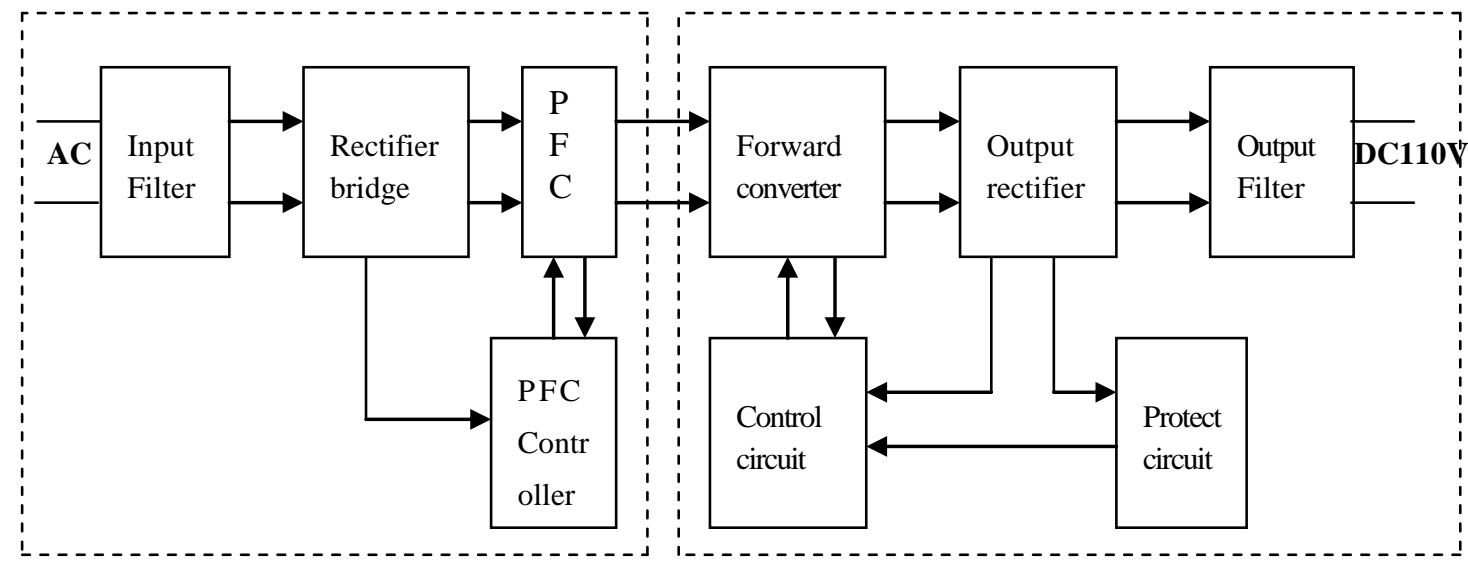

Fig.1 The Switching Mode Power Supply schematic diagram

\section{Design of Power Circuit}

2.1 The design of control mode of CCM with PFC based on average current mode circuit

PFC circuit is controlled by the idea of a current or voltage control of power electronic devices, ,so that the grid side input current will track the input voltage. Power electronic device absorption undistorted of the sinusoidal current absorption from the electricity grid. And the input is equivalent to a pure resistance; Power factor is equal to 1 . Depending on the inductor current is continuous or not, PFC circuit mode is divided into discontinuous conduction mode and continuous conduction mode. The device uses the average current with PFC of the CCM, Its characteristics are that total harmonic distortion (THD) and electromagnetic interference (EMI) is small, and more noise-insensitivity. It is also suitable for high power applications. The core control chip is UC3854 average current mode controller of Unitrode Company. Figure 2 is a schematic circuit diagram.

Power circuit from the rectifier bridge, the boost inductor $\mathrm{L}$; switch $\mathrm{V}$, the output capacitor $\mathrm{C}_{0}$ composed boost circuits. The control circuit uses average current mode control chip UC3854, it s core is a current regulator that consists of multiplier, the current error amplifier, PWM controller. As the influence of the current regulator, the input current tracks the input voltage and the waveform is sinusoidal, and they have the same phase

As the effect of pump up from boost inductor $\mathrm{L}$ and voltage hold function from capacitor $\mathrm{C}_{0}$, the output voltage is higher than the peak value of the input voltage. Meanwhile, according to changes in the feedback control circuit voltage $\mathrm{U}_{0}$, control circuit adjust the duty cycle of the switch to ensure that the output voltage constant when the input voltage fluctuate, thus providing a constant operating voltage for the converter stage. 


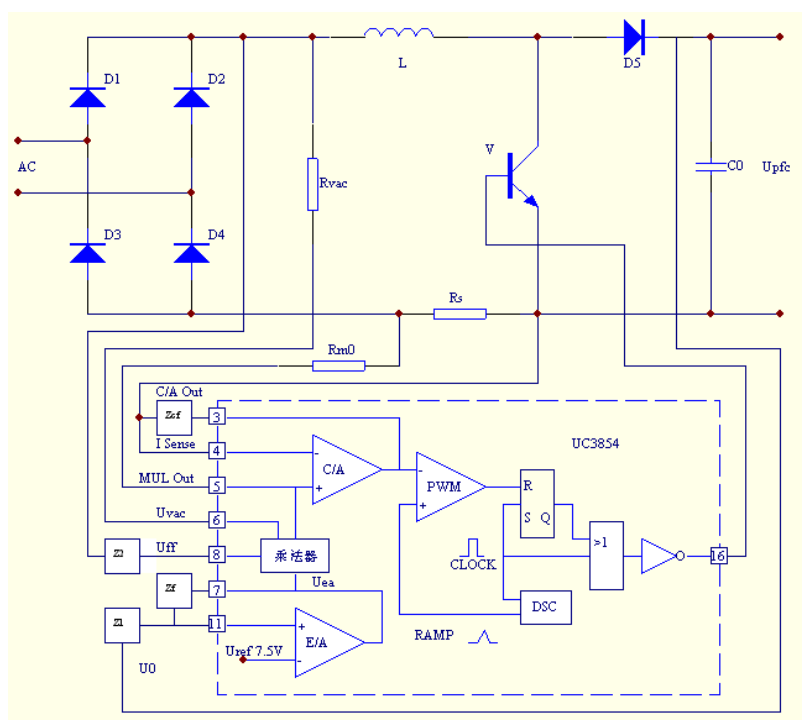

Fig2.PFC principle diagram

There are three input signals in control chip UC3854 multiplier, they are sampling signal of input voltage of the full-wave rectified $U_{\mathrm{VAC}}$, the output voltage of voltage error amplifier $\mathrm{U}_{\mathrm{EA}}$ and Squaring the input signal of the rectified voltage $\mathrm{U}_{\mathrm{ff}}$. Using three input signals for the operation $\left(U_{V A C} \times U_{E A}\right) / U_{f f}$ In the multiplier can produce a current reference signal the same phase and waveform with the input voltage and the input power does not vary with the input voltage, the circuit thus has a good dynamic response and load adjustment feature. Current of multiplier produces a given signal flowing through $\mathrm{R}_{\mathrm{mo}}$ and produce a voltage signal the same phase and waveform as the input voltage. voltage signal sampling and sampling resistor Rs generates a voltage signal $\mathrm{U}_{\mathrm{s}}$ which is applied to the input of the error amplifier, current error amplifier output voltage generates a drive signal for switch $\mathrm{V}$ with a triangular wave voltage modulated in PWM controller, so that the input current waveform follows the input voltage to provide power within the entire cycle for load. 2. 2 Design of dual interleaved forward converter

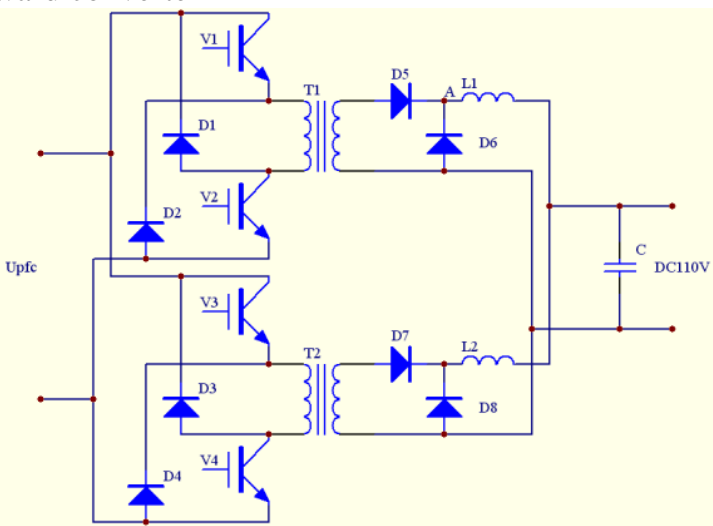

Fig3. Double-tube forward converter principle diagram

Two-transistor forward converter use IGBT as the switching element. The circuit consists of DC chopper and high-frequency rectifier filter. Principles of circuit as follows:

$\mathrm{V}_{1}$ and $\mathrm{V}_{2}$ are simultaneously turned on or off. The new cycle begins: because the conduction of $\mathrm{V}_{1}$ and $\mathrm{V}_{2}$, the secondary windings establish induced electromotive force, secondary rectifier diode $\mathrm{D}_{5}$ then conducts the current of freewheeling diode $\mathrm{D}_{6}$ decreases. When the forward current of $\mathrm{D}_{5}$ add to the original value of the current flowing through the $\mathrm{D}_{6}, \mathrm{D}_{6}$ turn off, the circuit starts the forward energy transfer condition.

When the switch $V_{1}$ and $V_{2}$ conduct, input voltage is applied to the primary winding $\mathrm{N}_{1}$ of the transformer, secondary winding $\mathrm{N}_{2}$ of Transformer induces a voltage, the output voltage is $\mathrm{U}_{0}$.

When the switch $V_{1}$ and $V_{2}$ turn off instantly, the secondary winding voltage reverse. Rectifier diode $D_{5}$ off. The freewheeling diode $\mathrm{D}_{6}$ conducts and constitute continuing current circuit because of the effect of $\mathrm{L}_{1}$. After $\mathrm{D}_{6}$ conducting, the voltage of "A" point is same as the load. The voltage across of $\mathrm{L}_{1}$ is the load voltage $\mathrm{U}_{0}$. When L-freewheel gradually reduce to the original starting value because of the load, Switch switch $\mathrm{V}_{1}$ and $\mathrm{V}_{2}$ conduct again, and they start a new working cycle. Because the interval of operating times between $V_{1}, V_{2}$ and $V_{3}, V_{4}$ is 180 degrees and others are same, so this article just analyze the working principle of $\mathrm{V}_{1}$ and $\mathrm{V}_{2}$.

2.3 The design of the main components' parameters of power circuit

In the process of designing, make sure the main parameters of power source are as follows: Input voltage AC is $150-280 \mathrm{v}$;Output voltage $\mathrm{DC}$ is $110 \mathrm{~V}$ : Maximum output current is $60 \mathrm{~A}$; the working frequency of $\mathrm{PFC}_{\text {is }} 20 \mathrm{KH}_{\mathrm{Z}}$; the working frequency of double forward convertor is $60 \mathrm{KH}_{\mathrm{Z}}$.

2.3.1 Design of boost inductor 
When BOOST PFC circuit works in the CCM mode, inductor designing should follow the principle of keeping the current continuous the inductor satisfies the following formula:

$$
L \phi \frac{U_{m}^{2} R_{L} T_{S(P F C)}}{4 U_{P F C}^{2}}
$$

In the formula: $\mathrm{U}_{m}$ is the peak of input voltage, $\mathrm{R}_{\mathrm{L}}$ is $\mathrm{PFC}$ load resistor, $\mathrm{T}_{\mathrm{S}(\mathrm{PFC})}$ is the switching period, $\mathrm{U}_{\mathrm{PFC}}$ is the $\mathrm{PFC}$ output voltage.

The load resistance $\mathrm{R}_{\mathrm{L}}$ of $\mathrm{PFC}$ is determined as follows:

Ignore the transmission loss of circuit, PFC output power(double forward converter input power) equals to Double Forward Converter output power, $\mathrm{I}_{\mathrm{L}(\max )}$ was $\mathrm{PFC}$ maximum output current, $\mathrm{I}_{0(\max )}$ is the maximum output current of power source. Therefore:

$$
\begin{gathered}
U_{P F C} \times I_{L(\max )}=U_{0} \times I_{0(\max )} \\
I_{L(\max )}=\frac{U_{0} \times I_{0(\max )}}{U_{P F C}} \\
R_{L}=\frac{U_{P F C}}{I_{L(\max )}}
\end{gathered}
$$

Make $\mathrm{U}_{\mathrm{m}}=396 \mathrm{~V}$, The output voltage of PFC $\left(\mathrm{U}_{\mathrm{PFC}}\right)$ is $400 \mathrm{~V}, \mathrm{~T}_{\mathrm{s}}$ is $50 \mathrm{us}, \mathrm{R}_{\mathrm{L}}$ is $16.5 \Omega$.

$$
L \phi \frac{U_{m}^{2} R_{L} T_{S(P F C)}}{4 U_{P F C}^{2}}=202 \times 10^{-6} \mathrm{H}
$$

The design of power supply, taking consideration of transmission loss and inductance magnetic saturation problem, the boost inductor is $400 \mu \mathrm{H}$.

2.3.2 Design of PFC circuit output capacitance $\mathrm{C}_{0}$

Selection of the PFC circuit output capacitance is related to the concept of hold time. Hold time is the output voltage which could be kept approximately constant within a certain time when the input power interrupts. Define the certain time as the hold time. The hold time is expressed by "thold"

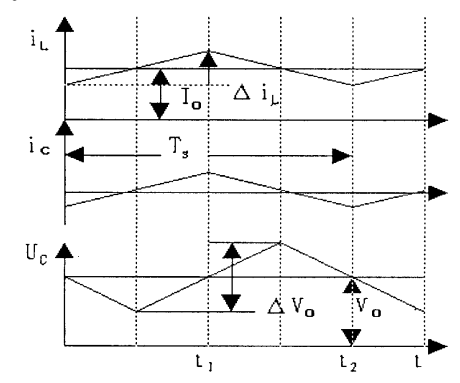

Fig. 4 The relation of parameter

The selection of output capacity of the capacitor is associated with the requirement of power source with output ripple voltage $\Delta U_{P F C}$. As shown in Figure 4 , When $\mathrm{i}_{\mathrm{c}}$ is a linear function about time $\mathrm{t}$ :

$$
\Delta U_{P F C}=\frac{1}{C} \int_{t_{1}}^{t_{2}} i_{c} d t=\frac{1}{C}\left(\frac{1}{2} \times \frac{\Delta I_{L}}{2} \times \frac{T_{S(P F C)}}{2}\right)=\frac{\Delta I_{L}}{8 C} T_{S(P F C)}
$$

So we can get:

$$
C=\frac{\Delta I_{L}}{8 \times \Delta U_{P F C}} \times T_{S(P F C)}
$$

make $\Delta I_{L}=10 \mathrm{~A}, \Delta U_{P F C}=0.1 \mathrm{~V}$, then:

$$
C=\frac{\Delta I_{L}}{8 \times \Delta U_{P F C}} \times T_{S(P F C)}=625 \times 10^{-6} \mathrm{~F}
$$

In the design of power supply, considering extending hold time as soon as possible, select the four electrolytic capacitors which is $2200 \mathrm{UF} / 400 \mathrm{~V}$. Use the connection of pairs in series and then connected in parallel. In addition, in order to improve the reliability of power supply. the range of electrolytic capacitor working temperature is $-40^{\circ} \mathrm{C} \sim 105^{\circ} \mathrm{C}$.

\section{Design on control circuit}

3. 1 Voltage and current double-loop feedback control model design

The traditional constant switching power supply using voltage-control mode, only the output voltage is sampled as a feedback signal to realize closed-loop control, so that the stable output voltage can be gotten. In the control process, the 
inductor current in the power supply circuit is not involved in the control, it is an independent variable, the switching converter is a second order system with two state variables: output voltage of filter capacitor and output current of the filtering inductance. Two order system is a conditionally stable system. Only when the design of the control circuit meets certain conditions, can the closed-loop system run stably. Switching power supply currents all flow through the inductor, so that contrast to the voltage signal of filter capacitor current signal has a delay of $90^{\circ}$. Therefore only by method of voltage sampling, has disadvantage of slow response, poor stability, and even large changes in the oscillation signal, thereby the power devices are easy damaged

In order to deal with the disadvantage of single voltage loop, the voltage and current loop control is set up in the device, so the current feedback loop is increased, and the inductor current is no longer an independent variable, so that the switching converter becomes a first-order unconditionally stable system. It has only a single pole and a phase lag of 90 . So it's easy to get the unconstrained large open loop gain and the perfect small signal and large signal characteristics. Principle diagram as follow:

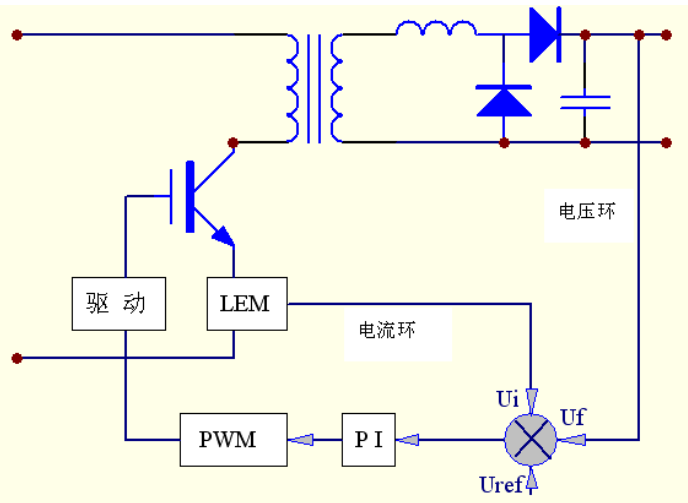

Fig.5 Double-loop control principle diagram

By double-loop control circuit good linear adjustable and fast dynamic response of the input and output can be gotten; Eliminating the poles brought by the output filter inductor and second-order properties of the system, so that the system has the best large-signal characteristics; Inherent by-pulse current limiting simplifies over load and short circuit protection, and automatic current is easy to implement by multiple parallel power supply unit.

3.2 Designing of the control mode with constant voltage and limited current output

In the two level switching converters with a power factor, the main purpose of the first level BOOST PFC circuit is the output stability of PFC in a wide range of input voltage condition, and improves the power factor. The second level interleaved two-transistor forward converters with the aim of regulating the output load matching. Therefore, the output control mainly refers to the two-transistor forward converter. When the battery charge is insufficient or long-term use, Result in lower battery terminal voltage, which appears with the DC output power greater pressure. lead-acid battery internal resistance is very small. Basically in milliohms level, in the power supply electrifying moment, large pressure difference will bring a larger charging current. On one hand the larger charging current can cause damage to the power supply over-current, on the other hand it will damage the battery. Therefore, the constant voltage and limited current controlling method is used in two-transistor forward converter.

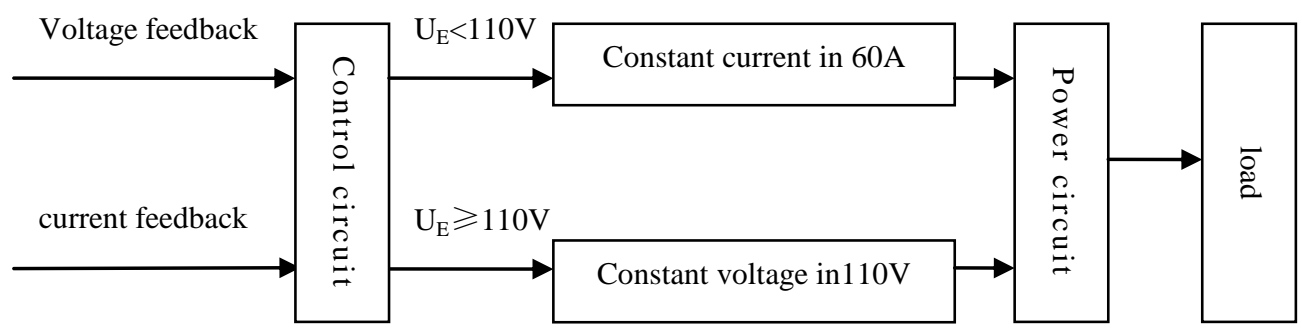

Fig.6 Charging control logic diagram

After the power supply, it should be determined whether the battery voltage is $110 \mathrm{~V}$ or not. If it is not reached, the controlling method should be the constant current output control in 60AWhen the battery voltage reaches $110 \mathrm{~V}$, the circuit switched to $110 \mathrm{~V}$ constant pressure control. It avoids the battery voltage is too low to bring a large current impact when the electric source connect to a current. It can not only protect the device, but also protect the battery.

\section{Prototype and test results}

According to the design, we developed a $110 \mathrm{~V}$ constant voltage power supply, and the main technical parameters are as follows: Input voltage ac150-ac280v; Output voltage DC110V $\pm 1 \%$ :Maximum output current 60A; working frequency $20 \mathrm{KH}_{\mathrm{Z}}(\mathrm{PFC}), 60 \mathrm{KH}_{\mathrm{Z}}$ (Double Forward Converter); $\mathrm{COS} \varphi \geq 95 \% \geq 95 \%$.

The power source is set up soft start, output overvoltage protection (the protection value is $120 \mathrm{~V}$ ), and reverse battery protection function. Under the conditions in laboratory, we test the power supply. We use $20 \mathrm{KW}$ single-phase 
autotransformer as the input power supply, the input voltage by manual adjustment is between AC 150 to AC $280 \mathrm{~V}$. and we use four $24 \mathrm{~V}$ lead-acid batteries in series with the battery pack and $3 \Omega / 10 \mathrm{KW}$ slider resistor in parallel. We adjust the output power by adjusting the slider resistor values, then, the experimental results show, under the various conditions, the power can be reliable. The figure below shows the experimental wave forms As the figure shows, the input current can follow the input voltage waveform well. And the output voltage remains stable under full load and input voltage variations.

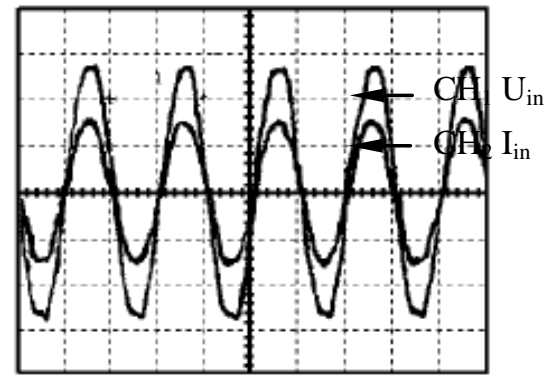

Fig.7 The wave of input current and voltage (time staff gauge:10ms/div; voltage staff gauge:CH1 50v/div; $\mathrm{CH} 25 \mathrm{~A} / \mathrm{div}$ )

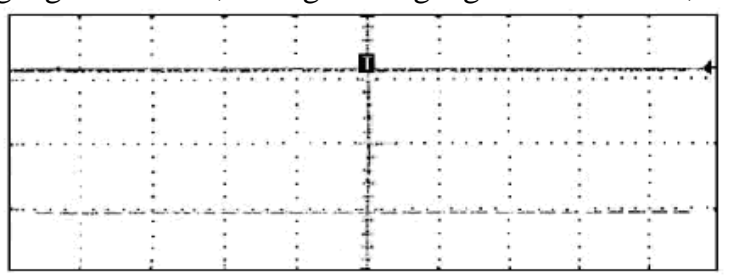

Fig.8 The wave of output voltage (time staff gauge: $25 \mathrm{us} / \mathrm{div}$; voltage staff gauge: $50 \mathrm{v} / \mathrm{div}$ )

\section{Conclusions}

This paper discusses the main parameters of the battery with a power factor correction two level converter structure of the charging power supply design process, and completes the design the prototype. The device has a wide input voltage range and is suitable for charging all types batteries. Because the device uses two structures, its input power factor is greater than single-stage switching power supply and the conversion efficiency of this device is slightly lower than the single-stage switching power supply. The experiments indicate that the device get good performance on output and reliability. The source is appropriate for all types of Battery charging.

\section{References}

[1] Weiping Zhang. Green Power[M].Beijing: Science Press,2001.p.3.

[2]Zhansong Zhang,Xuansan Cai. The Principle and Design of Switching Power Supply [M].Beijing:Publishing House of Electronic Industry,2003.p.370-373.

[3]Keith billings,Zhansong Zhang. Switch Mode Power Supply Handbook [M]. Beijing:Post\&Telecom Press,2006. 